\title{
Abstracts of the annual scientific meeting of the Association of Clinical Cytogeneticists held on 3 to 5 July 1991 at Earnshaw Hall, Sheffield
}

\section{The demography of Down's syndrome}

D E MUTTON, R IDE, E ALBERMAN, M BOBROW

The National Down Syndrome Cytogenetic Register, Department of Epidemiology and Medical Statistics, The London Hospital Medical College at $Q M W$, Mile End Road, London E1 4NS.

Based on information from the 2096 cases now in the NDSCR for $1989 / 90$ and after correction for natural fetal loss, the national birth prevalence for trisomy 21 would have been $1 \cdot 4 / 1000$, had no affected pregnancies been terminated. On the same basis regional rates would have varied between 1.2 and $1 \cdot 7 / 1000$. The differences depend in part on the regional maternal age distribution (mean maternal age ranging from $<26$ in the Northern RHA to $>28$ in SW Thames RHA). The age specific risk calculated on 1852 cases for whom we have a maternal age shows that, apart from the upper and lower tails where numbers are small, the rates are close to those published by Cuckle et al (Br $\mathcal{F}$ Obstet Gynaecol 1987;94:387-402). This register is providing a powerful database for epidemiological studies to identify other factors affecting regional risk variations.

\section{Interstitial deletion and normal phenotype: a new family and brief review}

\section{J BARBER, K COLES, D GRIFFIN,} J DELHANTY, R EDE

Wessex Regional Genetics Laboratory, General Hospital, Fisherton Street, Salisbury SP2 $7 S X$.

An interstitial deletion of chromosome 5 (del(5)(?q15?q22)) was found in an institutionalised woman of 44 referred for cerebral palsy. An apparently identical deletion was found in her phenotypically normal 79 year old mother. The father's chromosomes were normal. Neither mother nor daughter has a history of colon cancer, and initial molecular results suggest that the FAP locus is not included in the deleted segments. A review of analogous cases suggests that euchromatic interstitial deletions and duplications with normal phenotype are not confined to $G$ dark bands. While all reported pedigrees continue to show a consistently maternal or consistently paternal pattern of inheritance, the possible role of imprinting in imbalances with normal phenotype remains unresolved.

\section{Active centromeres in constitutional dicentric chromosomes}

\section{M CLARKE, S A ZWOLINSKI}

Cytogenetics Laboratory, Middlesborough General Hospital, Ayresome Green Lane, Middlesborough.

Inactivation of one centromere is the norm in constitutional dicentric chromosomes. Tis- sue culture from an 18 week intrauterine death showed a dicentric chromosome 11 with two active centromeres in all cells. The mitotic products predicted for a chromosome with two active centromeres were present in both cultures. The father carries the dicentric chromosome 11 but one centromere is inactive. In contrast to this $\operatorname{dic}(11)$ with centromeres in close proximity, a case is presented where the long arm of chromosome 2 separated the centromeres in a familial heterodicentric product of a 2;15 translocation. The stable active centromere is that of chromosome 2 .

\section{Trisomy $16 p$ in a liveborn offspring}

\section{LEONARD*, J L HURET}

${ }^{*}$ Cytogenetique, CHU Bicetre, Le Kremlin Bicetre; †Cytogenetique, Lab Hematologie, CNRS 1338 CHU la Miletrie, Poitiers, France.

We report on a case with trisomy for 16 p11.1 $\rightarrow$ pter and review 17 previous cases. The syndrome is monomorphic with a round face, microcephaly, scant hair, tiny nose, upper lip overhanging the lower lip, malformed extremities, and neurological and cardiovascular abnormalities. Frequently, respiratory distress leads to death in infancy. The region of overlap which causes the full phenotype is $16 \mathrm{p} 13.1-\mathrm{p} 13.3$. Most cases are inherited. Segregation is 3:1 in half of the cases. The other chromosomes involved in the translocations as well as their breakpoints appear to be non-random.

\section{A girl with familial $X ; Y$ translocation and mosaicism for an $18 q$ - deletion}

R ELLIS, C TOOP, M J A CRAWFORD Kennedy Galton Centre, Clinical Research Centre, Northwick Park Hospital, Watford Road, Harrow, Middlesex HA1 3UF.

Familial $\mathrm{X} ; \mathrm{Y}$ translocations in females generally present with short stature, and sometimes limb shortening as the consistent abnormalities. The $18 \mathrm{q}-$ syndrome is a well documented autosomal deletion syndrome with characteristic features including brachycephaly, midline hypoplasia and other facial dysmorphisms, heart defects, toe abnormalities, and genital hypoplasia. We present a girl with clinical features of the 18qsyndrome who was found to be mosaic for $18 \mathrm{q}$ - but in addition had an $\mathrm{X} ; \mathrm{Y}$ translocation. This was subsequently found to have been inherited from her mother, who has short stature. We review the previously reported cases of females with $\mathrm{X} ; \mathrm{Y}$ translocations.

\section{Chromosomal repair in normal and radiosensitive cells}

\section{R A F MACLEOD, P E BRYANT}

Deutsche Sammlung von Mikroorganismen und Zellkulturen $\mathrm{GmbH}$, Mascheroderweg $1 b$, 3300 Braunschweig, FRG.

We show in $\mathrm{X}$ irradiated, postsynthetic phase, human lymphocytes and CHO cells that the frequency of chromatid breaks declines exponentially after induction/expression, and that these kinetics probably reflect the repair of DNA double strand breaks (dsb) rather than either a progressively increasing chromosomal radiosensitivity or the removal of more heavily damaged cells in G2. In the radiosensitive, dsb repair deficient, $\mathrm{CHO}$ derived cell line XRS- 5 the rate of chromatid rejoining is equal to that of the wild type cells, confirming the usefulness of XRS-5 as a model for ataxia telangiectasia, for which we previously obtained similar repair kinetics in immortalised fibroblasts. Together these results suggest that only a subclass of dsb may be converted into chromosomal damage, as initial dsb inducibilities are believed similar in normal and radiosensitive cells, and that $\mathrm{G} 2$ kinetics provide a reliable quantitative endpoint for the study and diagnosis of chromosomal radiosensitivity.

\section{Evaluation of chromosomal damage following allogeneic bone marrow transplant in a patient with Fanconi's anaemia}

\section{R T HOWELL}

$S W$ Regional Cytogenetics Centre, Southmead Hospital, Bristol BS10 5NB.

Fanconi's anaemia was confirmed in a 6 year old boy by evaluation of mitomycin $\mathrm{C}$ and nitrogen mustard induced damage. $\mathrm{He}$ received a bone marrow transplant from his clinically unaffected brother in whom parallel cytogenetic assessment had shown normal responses to the same alkylating agents. Following transplant, regular three monthly cytogenetic monitoring of spontaneous and induced chromosomal damage was undertaken. After transplant, persisting host cells were identifiable by the presence of significant levels of induced aberrations, particularly chromatid exchanges and breaks. Chromosome type aberrations in the form of dicentrics and rings, not found before transplant, were also noted. Typical of radiation exposure, they also were indicative of host cell survival, pretransplant irradiation having been undertaken to reduce the bone marrow of the patient. Three months after transplant more than $40 \%$ of the cells examined showed evidence of recipient origin but a steady decline was observed in subsequent samples until, after one year, this figure had fallen to $3 \%$, indicating successful engraftment. Similar sister chromatid exchange frequencies in 
cultures exposed to the same treatment regimens enhanced confidence in the comparability between successive samples.

\section{Cytogenetic studies of PHA stimulated blood in BMT patients}

\section{P W THOMPSON, J A WHITTAKER \\ Department of Haematology, University Hospital of Wales, Heath Park, Cardiff.}

Chromosome studies on bone marrow aspirate from patients who have received an allogeneic bone marrow transplant (BMT) can be of great clinical value. The major disadvantage of this type of analysis is the lack of availability of material, and in an attempt to overcome this problem we have looked at the possibility of using PHA stimulated peripheral blood cultures to monitor patients post BMT. Serial cytogenetic studies were performed on patients who had received a sex mismatched BMT. In patients with a successful BMT a number of observations could be made: (1) no normal host lymphocytes were seen after day 7 post BMT, (2) by day 760 to $80 \%$ of cells were donor lymphocytes, the remainder being damaged host cells, and (3) after day 100 only occasional damaged host cells were seen. Two patients who relapsed during the study showed an abnormal cytogenetic picture in their blood before other clinical signs were evident.

\section{Cytogenetics in the pharmaceutical industry: GR63799, a clastogenic prostanoid?}

\section{A J BRICE et al Glaxo Group Research, Park Road, Ware, Herts SG12 ODP.}

GR63799, a drug candidate for treating disorders of gastric secretion, was evaluated in the human peripheral lymphocyte test to investigate the potential genotoxic effect. In the absence of metabolic activation GR63799 was clearly clastogenic in vitro. The drug breaks down rapidly to five degradation products. Two of these, benzamidophenol and the enone, were found to be clastogenic in the absence of metabolic activation. The metabolism scheme for the breakdown of GR63799 showed that benzamidophenol (the more potent clastogen) broke down further to the enone. The initial clastogenic effect was considered to be attributable to benzamidophenol. In the presence of metabolic activation, GR63799 and benzamidophenol were not clastogenic. It is proposed that benzamidophenol is detoxified in the presence of metabolic activation in a similar way to paracetamol. The drug candidate was not clastogenic in subsequent in vivo studies at doses far greater than the proposed therapeutic dose. Also benzamidophenol would be virtually undetectable in plasma at the therapeutic dose.

\section{The role of in vivo cell fusion in tumourigenesis and metastasis}

\section{N R PRATT}

Centre for Human Genetics, Langhill, 117 Manchester Road, Sheffield S10 5DN.

Detailed cytogenetic analysis of an HSV-2 transformed Syrian hamster tumour model (HSV-2-333-2-26) has provided evidence of spontaneous in vivo (tumour $x$ host) cell fusion in two of seven cell lines derived from metastatic lung deposits. The hybrid cells contained an almost complete extra diploid set of normal hamster chromosomes which alone might be considered highly suggestive of cell hybridisation. Further compelling evidence for fusion was provided by the presence of normal hamster chromosome $15 \mathrm{~s}$ in the hybrid cells. These chromosomes were only present in rearranged form in the original HSV-2 tumour cells and thus could only have been acquired from fusion with a normal cell. The phenomenon of premature chromosome condensation is known to be cytological manifestation of cell fusion and has been observed in a wide range of human cancers. This combined with the high modalities of many solid tumours (and in particular their metastases) suggests that cell fusion may have a significant role to play in human malignancy.

\section{Cytogenetic and molecular genetic study of the fragile $X$ syndrome}

\section{S J HAMILTON,}

R WHITTINGTON-SMITH, $K$ H TURNBULL, T ANDREWS, Y THAKKER, H KINGSTON, A P READ

North West Regional Cytogenetics Service, St Mary's Hospital, Hathersage Road, Manchester.

A total of 431 subjects with developmental delay were tested cytogenetically; 16 new probands were identified. An incidence rate of $5.03 \%$ for the selected population studied using the excess thymidine technique was obtained. Family studies involving cytogenetic and molecular genetic screening wer undertaken on 39 families with a view to giving more accurate carrier risk figures. The daughter of an obligate carrier was given risk of $0.1 \%$ of inheriting the fragile $\mathrm{X}$ gene using the probes RN1A and VK21A. Current strategy for prenatal diagnosis would involve molecular and cytogenetic sexing of chorionic villus sample. Molecular genetic testing for the fragile $\mathbf{X}$ gene would then be undertaken, on male fetuses only, using informative flanking markers. Fetal blood sampling would be recommended for cytogenetic testing in cases where there was inadequate information based on molecular testing alone.

\section{A single lymphocyte culture for fragile $X$ induction and prometaphase chromosome analysis}

M C STRACHAN, $M$ J GRIFFITHS

Regional Cytogenetics Unit, Birmingham Maternity Hospital, Edgbaston, Birmingham B15 2TG.

A single lymphocyte culture system is described which produces both reliable fragile $\mathrm{X}$ expression and elongated chromosomes for prometaphase analysis. This system which is based on that described by Wheater et al (F Med Genet 1987;24:113-4), involves the deoxycytidine release of a thymidin block. Eight fragile X positive subjects from five families had an average expression leve of $26 \%$, with a range of $12 \%$ to $45 \%$, using the thymidine/deoxycytidine protocol. This was comparable to the levels obtained in parallel cultures treated with thymidine alone (average $21 \%$, range $8 \%$ to $37 \%$ ) or fluorodeoxyuridine (average $20 \%$, range 5\% to $32 \%$ ). Using the thymidine/deoxycytidine protocol would allow a laboratory to use single culture for most referrals for analysis of lymphocyte chromosomes with implications for saving both time and resources.

The application of direct and cultured chorionic villus (CV) preparations in cases of fetal loss: a preliminary study

N R PRATT

Centre for Human Genetics, Langhill, 117 Manchester Road, Sheffield S10 5DN.

In a preliminary study of 54 unselected cases the diagnostic use of direct and cultured trophoblast tissue was compared to that of conventional solid tissue culture in the cytogenetic evaluation of pregnancy wastage. The combined abnormality rate for direct and cultured CV preparations was $28 \%$ compared to only $11 \%$ for conventional solid tissue culture. A total of 15 abnormalities (eight numerical, seven structural) was detected. Over two thirds $(67 \%)$ of these were only observed in villus preparations whereas all abnormalities detected by conventional methods were also detected on the $\mathrm{CV}$ preparations. The poor success of the conventional protocol was the result of either maternal contamination or failure of culture. The high level of abnormalities found, and the apparent low level of false positive and false negative results, suggests that cytogenetic analysis of direct and cultured CV preparations provides an excellent alternative to conventional solid tissue culture for many categories of fetal loss.

\section{The chromosome abnormality database}

\section{$S$ MERCER, $M$ FITCHETT}

Department of Medical Genetics, Churchill

Hospital, Headington, Oxford OX $3 \mathrm{LF}$.

Funded as a distributed resource of the Human Gene Mapping Project, the principal purpose of this database is to link records of abnormalities reported in local laboratories with cell lines deposited at the human cel bank at Porton Down. A survey by questionnaire has elicited a promising response from potential contributors, but has also highlighted the diversity of methods of data storage, expected to be a major technical obstacle. Data stored may be divided into three groups. The first includes information to identify the case to the submitting lab, such as case numbers. The second group includes the karyotype as Paris Nomenclature, and the reasons for referral. The final group concerns the location and nature of any stored samples. Extrapolating from the data collected so far, we expect to exceed 50000 
records within the three year initial span of the project.

\section{A complex rearrangement associated with sex reversal and the Wolf-Hirschhorn syndrome: a cytogenetic and molecular study}

\section{K COLES, M MACKENZIE, J CROLLA, J HARVEY, J STARR, F HOWARD, P JACOBS}

Wessex Regional Genetics Laboratory, General Hospital, Salisbury SP2 7SX.

We report a male infant referred with multiple congenital abnormalities consistent with the Wolf-Hirschhorn syndrome. Cytogenetic analysis showed a chromosome complement of $46, \mathrm{XX}$ with a deletion of 4 p15.2 $\rightarrow 4$ pter and its replacement by material of unknown origin. The patient was positive for a number of $\mathrm{Yp}$ probes including SRY, the testis determining factor, and in situ hybridisation localised the Yp material to the tip of the short arm of one $\mathrm{X}$ chromosome. Using pDP230, a probe for the pseudoautosomal region, and $M 27 B$, which recognises a locus in proximal $\mathrm{Xp}$, the material translocated on to $4 \mathrm{p}$ was identified as originating from the short arm of the paternal $X$ chromosome. The most reasonable explanation for this complex rearrangement is two interchange events during paternal meiosis $I$, the first involving one $\mathrm{X}$ and a $\mathrm{Y}$ chromatid, and the second involving a 4 and the other $X$ chromatid. This has resulted in a sex reversed male with a $4 p$ deletion and additional, apparently active $\mathrm{Xp}$ material translocated on to $4 \mathrm{p}$. His karyotype is, therefore, $46, \mathrm{XX}-4,+\operatorname{der}(4) \mathrm{t}(\mathrm{X} ; 4)(\mathrm{p} 22.1 ; \mathrm{p} 15.2)$.

\section{A true telomeric translocation in a baby with Prader-Willi phenotype}

\section{A REEVE, A NORMAN,} P SINCLAIR, Y HAMEY, R WHITTINGTON-SMITH, A READ

Regional Cytogenetics Unit, St Mary's Hospital, Manchester M13 OfH.

We report a baby with a de novo unbalanced translocation between chromosomes 12 and 15. Her karyotype was $45, \mathrm{XX},-12,-15,+$ der (12)t(12;15)(pter $\rightarrow$ qter::q13 $\rightarrow$ qter). DNA marker studies showed that the translocation was paternal in origin. The baby lacked the paternal 15q11-q13 region and in keeping with this had the Prader-Willi (PWS) phenotype. The breakpoint on $12 \mathrm{q}$ was distal to D12S11 (lambda MS43) which maps to $12 \mathrm{q}$ 24.3-qter. Fluorescent in situ hybridisation using the synthetic telomeric probes (TTAGGG) ${ }_{7}$ and (AATCCC) ${ }_{7}$ showed that the $12 \mathrm{q}$ telomere was still present within the translocated chromosome. Thus the translocation was within or on to the end of the telomere of 12q. This unusual translocation is further evidence of an unexplained instability of the $15 \mathrm{q} 11-\mathrm{q} 13$ region.

\section{Maternal heterodisomy in Prader-Willi syndrome}

\section{GRIFFITHS, T WEBB, C HARDY, D CLARKE, M KILPATRICK, P FARNDON}

Regional Cytogenetics Unit, Birmingham Maternity Hospital, Edgbaston, Birmingham B15 2TG.

Two subjects with typical Prader-Willi syndrome are presented. They are not related and were ascertained by different methods In each case there was no evidence of a deletion of chromosome 15 , either cytogenetically or with the DNA probes D15S9, $D 15 S 10, D 15 S 12$, and $D 15 S 13$ from the q11 to q13 region of chromosome 15 . In both cases cytogenetic polymorphisms of the short arm of chromosome 15 suggests maternal inheritance of both chromosomes 15 with no paternal contribution. These observations were confirmed using the hypervariable DNA probes CMW-1 and pMS620 from chromosome 15. Both patients have materna heterodisomy for chromosome 15 .

\section{Meiotic analysis on ovaries from two fetuses with structurally abnormal karyotypes}

S J IMRIE, R M SPEED, R MORRISON, J BATCHELOR, G W LOWTHER, E BOYD

Duncan Guthrie Institute of Medical Genetics, Yorkhill Hospitals, Glasgow G3 8SF.

Meiotic analysis was performed on ovaries from two fetuses with reciprocal translocations, detected prenatally. Surface spread preparations were stained to show the pachytene synaptonemal complex structures. These were analysed with both the light and electron microscope. The first case was a fetus, terminated with spina bifida. The karyotype was found to be $46, X, t(X ; 13)$ (q13;p13) Analysis of meiotic preparations showed a total premeiotic block in oogenesis. This confirmed the cytogenetic observation of involvement of the critical region on the $\mathrm{X}$ chromosome in this translocation. Parental karyotypes were normal. The second case was a fetus terminated with the karyotype $46, X X,-22,+\operatorname{der}(22), t(9 ; 22)(q 34 ; p 13)$ mat Synaptonemal complex configurations were observed at pachytene. These were consistent with the bivalent, quadrivalent and trivalent and univalent configurations predicted from meiotic pairing models.

\section{Meiotic studies by fluorescence in situ hybridisation}

\section{A S H GOLDMAN, M A HULTEN}

DNA Laboratory, Yardley Green Unit, East Birmingham Hospital, Birmingham B9 SPX.

The identification of specific chromosomes in human testicular biopsy preparations has been limited to spontaneous banding patterns in pachytene cells and triple staining techniques in first metaphase cells. Recent improvements in in situ hybridisation technology have provided a new tool for overcoming this laborious and limited ability to identify meiotic chromosomes. (Pinkel et al.
Proc Natl Acad Sci USA 1986;83:2934-8.) Chromosome in situ suppression hybridisation (CISS) has been applied using the whole chromosome 6 specific library, pBS6, on fixed preparations of testicular biopsy from a normal male and a constitutional carrier of an insertion $(6 ; 7)$. It was possible to identify chromosome 6 clearly throughout all stages of meiosis, even at second metaphase where banding techniques fail. In the insertion $(6 ; 7)$ carrier the proportion of first meiotic segregants which carried the abnormal 7 with the insert of chromosome 6 material was determined, $63 / 130(48.5 \%)$ second metaphase cells carried the inserted 7 while $67 / 130$ $(52.5 \%)$ did not. This confirms, for the first time, a theoretically expected first meiotic segregation ratio of $1: 1$ for a normal chromosome versus a derived homologue bearing an insert.

\section{Abnormalities of chromosome 16 in acute myelogenous leukaemia}

D R BETTS, A Z ROHATINER, $S$ RASSAM, M EVANS, B GIBBONS Cytogenetics Laboratory, Department of Medical Oncology, St Bartholomew's Hospital, London EC1A $7 B E$.

We report 13 patients with abnormalities of chromosome 16 , all having acute myelogenous leukaemia (AML). The patients were divided into two groups, those with an $\operatorname{inv}(16)(\mathrm{p} 13 \mathrm{q} 22)$ and those with an abnormality of the long arm of chromosome 16 (abn(16q)). The majority of inv(16) patients were AML M4Eo and had morphologically abnormal eosinophils at some stage of their disease. The abn(16q) patients were a far more diverse morphological group, and although most had abnormal eosinophils during their disease it was seldom as marked as the inv(16) group. Patients with inv(16) were more likely to enter complete remission (CR) than those with abn(16q) but remission duration was short in most cases. These results support the view that $\operatorname{inv}(16)$ and abn(16q) should be considered as differen groups although in our experience neither group constitutes a favourable prognosis.

\section{Cytogenetics of undifferentiated and minimally differentiated acute leukaemias}

\section{J HUTCHINSON, E SINCLAIR Centre for Human Genetics, Langhill, 117 Manchester Road, Sheffield S10 5DN.}

The distinction between acute myeloid and acute lymphoid leukaemias is important in the basis of treatment. The majority of acute leukaemias fit into one or other category and are treated accordingly. Over a four year period, seven of our confirmed acute leukaemia cases were not readily classifiable by the FAB system. Cytochemical and immunophenotypic studies showed one undifferentiated acute leukaemia, one mixed lineage acute leukaemia, and five cases of minimally differentiated myeloid leukaemia (AMLM0). Two of the seven cases had a deletion of chromosome 21 , an abnormality previously reported in a few cases of AML. A further two cases had trisomy 13 as the sole abnormality, a finding previously associated with 
acute leukaemias of limited differentiation. (Sreekantaiah et al. Leukaemia 1990;4:781-5.) No other common abnormalities were present. Further cytogenetic studies are required on these rare types of leukaemia before any conclusion can be made with regard to prognostic significance.

\section{Experience with a malignancy audit}

S ARMSTRONG, J WATERS, G HARDY, M CREASY, M HULTEN

Regional Cytogenetics Laboratory, East

Birmingham Hospital, Bordesley Green East, Birmingham B9 5ST.

From October 1989 onwards a questionnaire was sent out with each cytogenetic report to the 24 haematologists using the service. The aim of this initiative was to discover what value cytogenetics were to diagnosis and management of the patients' diseases. For 1990 there has been a response rate of $77 \%$. The audit has confirmed that there are wide differences in the use made of cytogenetic results by clinicians. For CML the role of cytogenetics is clearly defined in that finding a Philadelphia chromosome is useful for confirmation, for disease monitoring, and for assessment of status after bone marrow transplantation. For AML and ALL the value of cytogenetics is less clear. For AML this may be because specific abnormalities will only be found in a minority of cases. In our experience for ALL, cytogenetics is failing to make an impact on assessment or prognosis and in less than $30 \%$ of cases were cytogenetic results found to be useful.

\section{A novel polymorphism with the pericentomeric probe D15Z1}

K STERGIANOU, C GOULD, J WATERS, M HULTEN

Regional Cytogenetics Laboratory, East

Birmingham Hospital, Birmingham B9 5ST.

We have made extensive use of the multicopy, chromosome specific, centromeric probe, D15Z1 (satellite III type) which at low stringency corresponds to DA/DAPI staining, but at high stringency specifically hybridises to the $\mathrm{p}$ arm of chromosome 15 . We have screened 100 subjects with this probe at high stringency. In 88 subjects the expected two spots were seen at or just above the centromere on chromosome 15; in a further 12 subjects three spots were seen. Pre-G banding and combined use of D15Z1 with chromosome specific libraries showed that in each case a copy of chromosome 14 was labelled. This polymorphism appears to have no phenotypic effect and to be inherited in a simple Mendelian manner. This finding has implications for the use of such probes in prenatal and malignancy interphase screening.
Chromosome painting in clinical cytogenetics

C GOULD, E PARTON, K STERGIANOU, A MERCER, S HILL, J WATERS, P LEEDHAM, $M$ HULTEN Regional Cytogenetics Laboratory, East Birmingham Hospital, Bordesley Green East, Birmingham B9 SST.

We set out three main areas for the use of this technology in our laboratory. These are as follows. (1) Screening for aneuploidy or rearrangements, where using 'painting' a large number of cells can be screened quickly and very poor quality metaphases can be used. (2) Detection and confirmation of structural rearrangements, examples being $t(6 ; 15)(q 15$; $\mathrm{q} 26)$, and a dir ins $(7 ; 6)$ (q21.2;q16q23.1) using libraries pBS 6,7 , and 15 . (3) The identification of extra material of unknown origin by examples of a $3 p+$ which was shown to be $a \operatorname{der}(3) t(3 ; 8)(\mathrm{p} 26 ; \mathrm{p} 21.3)$, and a $2 \mathrm{q}+$ that was shown to be inv $\operatorname{dup}(2)(\mathrm{q} 34 \rightarrow \mathrm{q} 37)$. All libraries were obtained from the Lawrence Livermore National Library, USA. Hybridisation was carried out by the protocol set out in Pinkel et al. Proc Natl Acad Sci USA 1988;85:9138-42.

\section{Chromosome painting: suppression or depression}

M N ISA, E BOYD, J M CONNOR

Duncan Guthrie Institute of Medical Genetics, Yorkhill Hospitals, Glasgow G3 8Sf.

A chromosome 21 specific library obtained from ATCC has been used to develop chromosome painting or chromosomal in situ suppression (CISS). The main problems with chromosome painting are the preparation of the probe (which includes labelling), poor suppression, high background signal, non-homogeneous painting, and poor hybridisation. Library amplification and purification, probe labelling, pre- and posthybridisation procedures and fluorescent detection have all been investigated.

\section{Characterisation of sex chromosome derived marker and ring chromosomes in mosaic form using non-isotopic in situ hybridisation}

P SINCLAIR*, F COLLIER $†$, M BUTTERWORTH $\dagger, J$ HASLAM*, A REEVE*, T ANDREWS*

*Regional Cytogenetics Unit, St Mary's Hospital, Manchester; †Regional Cytogenetics Unit, St fames's Hospital, Leeds.

Characterisation of sex chromosome derived marker and ring chromosomes in mosaic form may present problems using conventional cytogenetic techniques. In situ hybridisation using a Yp specific probe has been used to investigate a $46, \mathrm{XY} / 46, \mathrm{X},+$ mar karyotype found in a normal male. The results suggest that the marker is of $\mathrm{Y}$ origin and not isodicentric. Characterisation of a Turner ring mosaic using in situ hybridisation with chromosome specific centromeric probes indicated that the ring was of $X$ origin. Further studies showed that the human telomere sequence (TTAGGG)n was missing from the ring $\mathrm{X}$ but present on the apparently terminally deleted marker chromosome in normal abundance. This finding suggests either that the deletion is interstitial rather than truly terminal or that the broken chromosome ends have been 'healed' by addition of this sequence.

Towards molecular localisation of a human gene for spermatogenesis

A C CHANDLEY, K MA,

T B HARGREAVE, A SHARKEY, P VOGT*

MRC Human Genetics Unit, Western General Hospital, Edinburgh EH4 2XU;

*Institut fur Humangenetik und Anthropologie der Universitat, Im Neuenheimer Feld 328, 6900 Heidelberg 1, Germany.

Genotype-phenotype correlations suggest the location of a gene controlling spermatogenesis (AZF or azoospermia factor) in band q11.23 of the human Y chromosome (Tiepolo and Zuffardi. Hum Genet 1976;34:11924). Molecular analysis is currently being undertaken to define the limits of AZF within Y chromosome interval 6 of Vergnaud. The AZF sequences appear to be at least partially conserved from a fertility gene on the Drosophila $\mathrm{Y}$ chromosome.

\section{The application of in situ hybridisation with $Y$ chromosome probes in diagnostic cytogenetics L R WILLATT, S L WOOD, M E FERGUSON-SMITH, M A FERGUSON-SMITH}

East Anglian Region Cytogenetics Laboratory, Addenbrooke's Hospital, Cambridge.

In situ hybridisation has provided the definitive diagnosis for more than 20 cases of sex chromosome abnormalities referred to this laboratory. Below we present our findings on six patients with a dicentric $\mathrm{Y}$ chromosome, three with a $\operatorname{dic}(Y p)$ and three with a $\operatorname{dic}(Y q)$. These cases are of special interest because of the different phenotypes associated with apparently the same $Y$ chromosome abnormality.

\begin{tabular}{|c|c|c|c|c|}
\hline Patient & Sex & Age (y) & $\%$ of cells $45, \mathrm{X} / 46, \mathrm{X}, \operatorname{dic}(\mathrm{Y})$ & Features \\
\hline $\begin{array}{r}\operatorname{dic}(\mathrm{Yq}) \\
2 \\
3\end{array}$ & $\begin{array}{l}\mathbf{F} \\
M \\
M\end{array}$ & $\begin{array}{l}61 \\
55 \\
\text { Adult }\end{array}$ & $\begin{array}{l}58 / 42 \\
16 / 84 \\
15 / 85\end{array}$ & $\begin{array}{l}\text { Turner phenotype } \\
\text { Azoospermia } \\
\text { Azoospermia }\end{array}$ \\
\hline $\operatorname{dic}(Y p) \begin{array}{r}4 \\
5 \\
6\end{array}$ & $\begin{array}{l}\mathrm{F} \\
\mathrm{F}\end{array}$ & $\begin{array}{l}10 / 12 \\
20 \\
31\end{array}$ & $\begin{array}{l}93 / 7 \\
94 / 6 \\
14 / 86\end{array}$ & $\begin{array}{l}\text { Failure to thrive } \\
\text { Ovarian cyst } \\
\text { Azoospermia }\end{array}$ \\
\hline
\end{tabular}




\section{Posters}

\section{Diagnostic application of chromosome painting to malignancies}

S J ARMSTRONG, R A JOHNSON, $S$ G LONG, C GOULD, M HULTEN, D MILLIGAN, J WATERS

Regional Cytogenetics Laboratory, East Birmingham Hospital, Bordesley Green East, Birmingham B95ST.

Applications of chromosome painting include characterisation of breakpoints in reciprocal translocations and identification of marker chromosomes. As conventional cytogenetic analysis can present particular problems with malignancies, we have modified fluorescence in situ hybridisation (FISH) (Pinkel et al. Proc Natl Acad Sci USA $1988 ; 85: 9138-42)$ to allow this technique to be applied to bone marrow specimens. Three cases are reported where FISH has been used in addition to $G$ banding to characterise acquired abnormalities. (1) Trisomy 8 in a case of accelerated chronic myeloid leukaemia was easily detected in very poor metaphases where unequivocal identification could not have been made. (2) Composition of a ring was determined to be entirely chromosome 19 in a case of acute myeloid leukaemia. (3) Trisomy 1 and $t(1 ; 19)$ was confirmed in a case of peripheral neuroectodermal tumour infiltrating bone marrow.

\section{Microdissection of band $8 \mathrm{q} 22$ for the molecular analysis of the $t(8 ; 21)$ breakpoint in AML M2}

\section{J BUNGEY, A DAGA, F CALABI \\ Department of Haematology, RPMS}

Hammersmith Hospital, East Acton, London.

Our aim is the molecular analysis of the $t(8 ; 21)(q 22 ; q 22)$ characteristic of acute myeloid leukaemia (AML) M2. To this end we are generating a large number of new probes mapping to the breakpoint regions. Normal human chromosomes are prepared from peripheral blood lymphocytes. After G banding $8 \mathrm{q} 22$ bands are manually microdissected. Approximately 20 bands are collected in a single tube and DNA is amplified from these by PCR with random primers. The amplified DNA is then cloned into a plasmid vector as well as used directly as a complex probe on genomic libraries. In this way, a minibank of around 10000 recombinants putatively derived from $8 \mathrm{q} 22$ has been established. Further characterisation of these clones is in progress, as a prerequisite to their use in Southern blotting of $t(8 ; 21)$ positive samples.

\section{The use of in situ hybridisation to exclude possible graft rejection after bone marrow transplantation}

\section{A CHASE, P DE FABRITIIS, J M GOLDMAN}

Department of Haematology, RPMS

Hammersmith Hospital, Du Cane Road, East Acton, London.

Cytogenetics on peripheral blood or bone marrow cannot easily be performed for several weeks following bone marrow transplantation. We have used in situ hybridisation (ISH) to study the proportions of donor and recipient cells, in interphase, in five patients who had recently received sex mismatched bone marrow transplant for chronic myeloid leukaemia and who appeared by haematological criteria to be rejecting their grafts. ISH was performed on Cytospin preparations of peripheral blood mononuclear cells, using the repetitive sequence probe $\mathrm{pHY} 2.1$. In each case normal male and female cells were used as controls and false positive and false negative cells had an incidence of usually less than $5 \%$. The results showed only cells consistent with donor origin in each of the four patients; there was therefore no evidence of graft failure in these cases.

\section{Cytogenetic and in situ hybridisation studies of non-Hodgkin's lymphoma}

D W HAMMOND, A M POTTER, B W HANCOCK, M H GOYNS

Department of Clinical Oncology, Royal Hallamshire Hospital, Sheffield, and Centre for Human Genetics, Sheffield.

We have studied karyotypes of cells isolated from a range of non-Hodgkin's lymphoma (NHL) biopsies. Abnormalities of $6 \mathrm{q}$ are present in over $25 \%$ of our cases and we have been using non-isotopic in situ hybridisation to map a series of DNA probes to chromosome 6 . The $M Y B$ proto-oncogene is known to be localised to $6 \mathrm{q} 22-23$ and a $2.6 \mathrm{~kb}$ probe for the $M Y B$ gene was hybridised to prebanded metaphases from two NHLs. The experiment showed apparent deletion of the $M Y B$ locus on one chromosome 6 in the first NHL and complex rearrangements of chromosome 6 in the second. These findings were not predictable from the previous $\mathrm{G}$ banding.

\section{'Jumping' translocations in meningiomas}

\section{S A ZWOLINSKI, C M CLARKE}

Cytogenetics Laboratory, Middlesborough General Hospital, Ayresome Green Lane, Middlesborough.

We report five meningioma cases with socalled 'jumping' translocations (Reis et al. Cancer Genet Cytogenet 1991;51:189-94).

Case I:

$42, \mathrm{XX},-1,-6,-8,-13,-14,-22$,

$+\operatorname{der}(1) t(1 ; 4),+\operatorname{der}(17) t(17 ; 21)$.

Case II:

$45, \mathrm{XY},-22, \mathrm{t}(2 ; 9)(\mathrm{q} 11 ; \mathrm{p} 13)$

Case III:

$44, \mathrm{XX},-19,-22 / 54, \mathrm{XX},+2,+3,+7,+10$, $+12,+13,+15,+17,+21,-22$.

In the first three cases $11 \mathrm{p}$ breakpoint translocations were involved in subclonal changes. These changes involved various chromosomes and always resulted in partial monosomy for $11 \mathrm{p}$.
Case IV:

$45, \mathrm{XX},-22, \mathrm{t}(15 ; 22)(\mathrm{q} 15 ; \mathrm{q} 12.3)$.

In case IV subclonal variations arose by translocations between chromosome 3 (at 3qter) and various other chromosomes.

Case V:

$42, \mathrm{XX},-1,-4,-9,-15,-18,-19,-22$ $+\operatorname{mar},+\operatorname{der}(1) \mathrm{t}(1 ; 4),+\operatorname{der}(9) \mathrm{t}(9 ; 15)$.

$42, \mathrm{XX},-1,-4,-9,-15,-18,-19,-22$, $+\operatorname{mar},+\operatorname{der}(1) \mathrm{t}(1 ; 9),+\operatorname{der}(4) \mathrm{t}(4 ; 15)$.

$42, \mathrm{XX},-1,-4,-9,-15,-18,-19,-22$,

$+\operatorname{mar},+\operatorname{der}(1) \mathrm{t}(1 ; 15),+\operatorname{der}(4) \mathrm{t}(4 ; 9)$.

The three subclones in case $\mathrm{V}$ differed only in the two dicentric markers derived by rearrangements of the same four chromosomes. The translocations at breakpoints $1 \mathrm{p} 13$, $4 \mathrm{p} 14,9 \mathrm{p} 13$, and $15 \mathrm{p} 1$ resulted in the loss of the same chromatin in all subclones.

\section{Cytogenetics of uveal melanoma}

K SISLEY, D COTTAM, I G RENNIE, A M POTTER, C W POTTER,

R C REES

Department of Experimental and Clinical Microbiology, Royal Hallamshire Hospital, Sheffield.

Posterior uveal melanoma is an ocular tumour derived from the choroid and ciliary body. Cytogenetic reports of this tumour have been limited; we previously reported six cases in which the involvement of chromosomes 3,6 , and 8 was observed. In this study we present a further 10 cases of posterior uveal melanoma. One tumour had a normal chromosome complement and a second showed loss of the $\mathrm{Y}$ chromosome. The remaining eight presented abnormal chromosome complements, with limited cytogenetic change. The most frequently involved chromosomes were 3, 6, and 8. Four ciliary body tumours had non-random association of monosomy 3 and $i(8 q)$ and abnormalities of chromosome 6 involving both the long and the short arm were found in five tumours.

\section{Cytogenetic analysis of a lipoma from a child}

\section{E L D MITCHELL, A KELSEY}

Department of Cancer Genetics, Paterson

Institute for Cancer Research, Christie

Hospital, Wilmslow Road, Manchester M20 9BX.

Despite a number of cytogenetic studies on lipomas from adults no cytogenetic data are available on lipomas in children. We report here cytogenetic data from a lipoma from a 12 year old male. Analysis of 11 cells showed the presence of ring chromosomes in nine cells. Five cells possessed one large ring, three cells possessed one large ring and one small ring, and one cell possessed one large and two small rings. The composite karyotype is $46-49, \mathrm{XY},+1-3 \mathrm{r}$. It was not possible to identify the origin of the ring chromosomes. 
Cytogenetic heterogeneity in $t(11 ; 19)$ acute leukaemias (AL)

J L HURET*, C CHARRIN $\dagger$, R SLATER $\ddagger$, M F BERTHEAS $\$$, A BRIZARD*, J TANZER*, A HAGEMEIJER $\|$

CHU Poitiers*, Lyon $\dagger$, and St Etienne\$, France, and Rotterdam $\|$ and Amsterdam University Hospitals, The Netherlands.

We report 16 cases of $t(11 ; 19) \mathrm{AL}$ and review updated data of 33 published cases. Four haematological groups were found: (1) B lineage $\mathrm{AL}$, mostly $\mathrm{CD} 19+(\mathrm{n}=13)$, (2) biphenotypic AL with CD19 and monocytic lineage markers $(n=8)$. These B lineage and biphenotypic AL were mainly found in female infants, (3) $\mathrm{T}$-AL in children $(\mathrm{n}=4)$, and (4) non-lymphocytic AL, generally M4 or M5, predominantly in males $(n=23)$ Cytogenetically, two subtypes were observed with an identical breakpoint on 11q23 but discrete breakpoints on 19p: lymphoid, biphenotypic, and most congenital myeloid cases showed a breakpoint on 19q13.3 (derivatives were $11 q-$ and $19 p+$ ), while most older myeloid cases had a more proximal breakpoint on $19 \mathrm{p} 12$ or 13.1 (with derivatives $11 \mathrm{q}+$ and $19 \mathrm{p}-$ ). The latter type was detected with $R$ bands but barely visible with $G$ bands, and vice versa for the former type. WBC is high and prognosis is poor in these $\mathrm{t}(11 ; 19) \mathrm{ALs}$, except in T-AL cases.

\section{Biphenotypic leukaemia associated with chromosome translocation $t(11 ; 19)$}

G ROBINSON, E MATUTES, M DYER, B CZEPULKOVSKI*, J SWANSBURY, $M$ FINDLAY, R POWLES,

$D$ CATOVSKY

The Royal Marsden Hospital and Kings

College Hospital*, London.

Because of the $11 \mathrm{q} 23$ breakpoint, it was originally thought that translocation $t(11 ; 19)(q 23 ; p 13)$ would be limited to monocytic leukaemia. However, it has been found to occur in four disease groups, pre-B ALL, biphenotypic acute leukaemia, T-ALL (in which the translocation appears to be associated with a relatively good prognosis), and ANLL (M4 or M5) (Huret et al, in press). The case described is a 13 year old boy with $t(11 ; 19)(q 23 ; p 13)$ and biphenotypic leukaemia, both $B$ cell and myeloid antigen being expressed, but is unusual in being an older child and having a low white cell count.

\section{Monosomy 17p: a new non-random finding in acute lymphoblastic leukaemia?}

J M HAWKINS,

L M SECKER-WALKER, C A SHIPPEY, M MARTINEAU, H G PRENTICE, A V HOFFBRAND

Academic Haematology, Royal Free Hospital and Medical School, Rowland Hill Street, London NW3 $2 Q G$.

Nine cases of acute lymphoblastic leukaemia (ALL) with abnormalities of $17 p$ are presented. Four had deletions at $17 \mathrm{p} 11$, two had unbalanced translocations at $17 \mathrm{p} 12$, two had isochromosomes resulting in loss of $17 p$, and one had a balanced translocation involving 17p13. Four of the cases were analysed at diagnosis and five at relapse. The patients were seven males and two females, with a median age of 15 years and white cell counts at diagnosis ranging from $1.4 \times 10^{9} / 1$ to $47 \cdot 1 \times 10^{9} / 1$. Their immunophenotypes were cALL (four cases), pre-B (one case), B cell (two cases), and T-ALL (two cases). Seven were pseudodiploid and two low hyperdiploid; all had additional structural abnormalities. Published cases include five with deletions of $17 \mathrm{p}$ in ALL, six with unbalanced translocations, and 18 with $i(17 q)$. This indicates that monosomy $17 p$ is a non-random finding in ALL, in which the putative antioncogene p53 located at $17 \mathrm{p} 13$ may be of relevance.

\section{Inv dup(14): a non-random finding in acute lymphoblastic leukaemia}

D M LILLINGTON, D R BETTS, L W KEARNEY, B GIBBONS

Cytogenetics Laboratory, Department of

Medical Oncology, St Bartholomew's

Hospital, London EC1A $7 B E$.

We report a possible new non-random chromosome abnormality in acute lymphoblastic leukaemia (ALL). Cytogenetic analysis of a 14 year old female presenting with Null ALL L2 and an 11 year old male presenting with cALL L1 showed the presence of an inv dup(14). We suggest that owing to the poor morphology of ALL chromosomes the incidence of this inv dup(14) may well be underrepresented in published reports.

\section{Reciprocal t(14;19)(q32.3;q13.1) \\ in a patient with acute lymphoblastic leukaemia}

\section{E SINCLAIR}

Centre for Human Genetics, Langhill, 117 Manchester Road, Sheffield.

A case of an acute lymphoblastic leukaemia (ALL) with a reciprocal $t(14 ; 19)$ is presented. Blast cell morphology and immunophenotype were characteristic of pre-B ALL (FAB type L1). The same rearrangement with breakpoints at bands $14 \mathrm{q} 32.3$ and 19q13.1 has previously been described in a few cases of B cell chronic lymphocytic leukaemia and non-Hodgkin's lymphoma and in one case of acute biphenotypic leukaemia. This is the first reported case to be seen in a pre-B ALL. Its detection before chemotherapy implicates the $t(14 ; 19)$ as a primary chromosomal abnormality. Variations in disease type associated with the translocation may reflect modifications of the rearrangement at the molecular level, or may be related to differences in the stage of cellular differentiation at which the molecular change occurs.

\section{Multiple structural rearrangements in a case of T cell ALL}

\section{OCANA GIL, S HARRIS,} C KITCHEN

South Western Regional Cytogenetics Centre, Southmead Hospital, Bristol BS106NB.

A 14 year old girl with a newly diagnosed $T$ cell ALL was found to have a complex clone with three separate rearrangements: (1) $t(11 ; 14)(p 13 ; q 11)$, a typical $T$ cell ALL abnormality, (2) $\mathrm{t}(4 ; 10)(\mathrm{q} 21 ; \mathrm{q} 24)$, which involved a breakpoint on chromosome 10 found in T cell ALL but usually in the form $t(10 ; 14)$, and the breakpoint on chromosome 4 found in non-T cell ALL in the familiar form $t(4 ; 11)$, (3) $i(9 q)$ again described in $T$ cell ALL. Thus the picture was consistent with $T$ cell ALL but it was not possible to ascertain the primary change or whether the rearrangements originated simultaneously.

\section{A need for cooperation between cytogenetic services}

$S$ LUNGLEY, $\mathrm{K}$ TURNBULL,

V PETROVIC, K OCRAFT, Y HAMEY, A DOUGLAS

North Western Regional Cytogenetics Service (Oncology), Christie Hospital, Manchester M20 9BX.

Two unrelated cases referred for acute lymphoblastic leukaemia (ALL) are presented. In both cases chromosome abnormalities were observed in $100 \%$ of bone marrow cells and PHA stimulated peripheral blood cells. Case 1. 46,XY,inv(9)(q32q34). The inversion was also observed in PHA stimulated peripheral blood from the patient's father. Molecular studies are currently being carried out to deduce whether a hidden bcr-abl rearrangement exists. Case 2. 46,XY,t(15;21)(p11; 111$)$. The translocation was not seen in the parental blood; the mother was four months pregnant and needed genetic counselling. Four cases of $t(15 ; 21)$ have been previously reported in ALL. We discuss the predisposition of these patients with constitutional chromosome abnormalities to acute leukaemia, and the need for close cooperation between the relevant departments of the cytogenetic service.

\section{Adaptive response of human lymphocytes to N-methyl $\mathbf{N}$-nitro $\mathbf{N}$-nitroso guanidine}

H RANDHAWA, D CURTIS

Sub-Department of Medical Genetics, University of Sheffield, Sheffield.

Repeated pretreatment of lymphocytes with low doses of an alkylating agent, $\mathrm{N}$-methyl $\mathrm{N}$-nitro $\mathrm{N}$-nitroso guanidine, followed by a subsequent challenge dose, leads to a decrease in the induction of cellular lesions (as measured by sister chromatid exchange analysis). Fifteen normal subjects, four immunosuppressed renal transplant recipients with skin cancer, and five immunosuppressed patients without skin cancer have been studied. Ten out of 15 normal subjects show an adaptive response. Eight out of nine immunosuppressed subjects show an adaptive response. This study is ongoing and more patients need to be included in order to make the results statistically significant. Some authors have suggested that the procedure outlined above does not yield reproducible results. Our study, in which some subjects have been tested up to 12 times, has shown high reproducibility of data. 
A case of Ph negative, bcr positive $C M L$ with translocation t(6;9)(p23;q34) but no rearrangement of can or dek

G J SWANSBURY, T MIN, M J S DYER, D JADAYEL, J HEWARD, J MAITLAND*

The Royal Marsden Hospital and ${ }^{*}$ Queen Mary's Hospital, London.

A 55 year old male patient was diagnosed as having chronic myeloid leukaemia (CML). Blood samples were sent for routine bcr analysis and cytogenetic studies. These showed the expected $b c r$ rearrangement but chromosomally a $t(6 ; 9)(p 23 ; q 34)$ instead of a $t(9 ; 22)(q 34 ; q 11)$. The $t(6 ; 9)$ typically occurs in about $0.5 \%$ of acute myeloid leukaemias, and is associated with TdT positivity and basophilia. The breakpoints cluster in genes dek at $6 \mathrm{p} 23$ and can at $9 \mathrm{q} 34.3$, approximately $300 \mathrm{~kb}$ distal to c-abl which is described as being at $9 \mathrm{q} 34.1$. In this patient, however, neither dek nor can were rearranged. Further studies are being made to determine the exact location of the breakpoint on $9 q$, already found to be unusual in being very near or beyond the $3^{\prime}$ end of $c-a b l$.

Residual BCR-ABL transcript in chronic myelogenous leukaemia (CML) treated with interferon and chemotherapy?

F X MAHON, J L HURET,

F GUILHOT, J TANZER

Cytogenetique, Lab Hematologie, CNRS

1338 CHU la Miletrie, Poitiers, France.

Polymerase chain reaction (PCR) was used to evaluate minimal residual disease in seven CML cases treated with interferon, hydroxyurea, and cytosine arabinoside, and where no $\mathrm{Ph}+$ mitoses were found for three to 24 months. RNA was isolated from peripheral blood lymphocytes. After generation of cDNA, a first step amplification with $5^{\prime}$ and $3^{\prime}$ primers was carried out, followed by a second PCR step with nested primers. Amplification showed no BCR-ABL rearrangement in three of the seven patients, while amplification controls (using interleukin 1) were positive. Recently, one of these three negative patients was found to show a BCR-ABL rearrangement after decreasing interferon treatment.

Two karyotypically similar cases with double minutes transforming to acute myeloid leukaemia

\section{H L DEELEY, A M BLISSITT}

Regional Cytogenetics Unit, Birmingham Maternity Hospital, Edgbaston, Birmingham B15 2TG.

Two cases are described in which cytogenetic analysis on fresh bone marrow samples showed similar complex karyotypes with double minutes. Both patients had transformed to acute myeloid leukaemia, one from myelodysplastic syndrome and the other from polycythaemia rubra vera. The clinical outcomes were, however, very different, with the former patient now dead and the latter patient achieving remission and receiving an autologous bone marrow transplant. One case has previously been reported (Gallagher et al. Blood 1979;54.3:713-33) which had a similar karyotype; however, this was in a transformed cell line HL- 60 .

\section{Trisomy 14 in haematological disorders}

\section{J L HURET, A BRIZARD,} F GUILHOT, J TANZER

Cytogenetique, Lab Hematologie, CNRS 1338 CHU la Miletrie, F-Poitiers, France.

We report on four cases of trisomy 14 as the sole anomaly (three myelodysplasias, one lymphoma), which brings to 21 the total number of reported cases (median age 64 years, range 40 to 84 years). These include five acute non-lymphocytic leukaemias, seven myelodysplastic syndromes, five atypical chronic myelogenous leukaemias, and two myeloproliferative syndromes. However, this anomaly is not restricted to the myeloid lineage but also appears to be a nonrandom anomaly in lymphoid disorders ( $n=2$ including ours). In a number of cases (three of $21,14 \%$ ), apparently unrelated abnormal clones were also found.

\section{Inv(16)(p13q22) in three cases of myelodysplasia}

C HARRISON, C SHIPPEY, Y COOK Regional Cytogenetics Service (Oncology), Paterson Institute for Cancer Research, Christie Hospital, Manchester M20 9BX.

We report three cases of myelodysplastic syndrome (MDS) with inv(16). Patient 1. $46, X X / 46, X X, i n v(16)(p 13 q 22)$. Patient 2. 46, $\mathrm{XX} / 46, \mathrm{XX}, \operatorname{inv}(2)(? \mathrm{q} 21 \mathrm{q} 33), \operatorname{inv}(16)(\mathrm{p} 13 \mathrm{q} 22)$. Patient 3. 46,XY $,+1,-20, \operatorname{inv}(3)(\mathrm{p} 13 \mathrm{p} 24)$, $\operatorname{del}(12)(\mathrm{p} 11 \mathrm{p} 12), \operatorname{inv}(16)(\mathrm{p} 13 \mathrm{q} 22) \cdot \operatorname{Inv}(16)$ is usually associated with acute myeloid leukaemia, with eosinophilia and abnormal eosinophils (M4Eo). A small number of cases have been reported of inv(16) in MDS, which usually show some eosinophilia. The three patients reported here showed no evidence of eosinophilia or abnormal eosinophils.

\section{Homozygous 13q14 breakpoint in chronic lymphocytic leukaemia}

\section{J L HURET, A BRIZARD, B DREYFUS, $\mathrm{J}$ TANZER \\ Cytogenetique, Lab Hematologie, CNRS}

1338 CHU la Miletrie, Poitiers, France.

A patient with chronic lymphocytic leukaemia (CLL) diagnosed in 1984 had a normal karyotype until 1991, where a clone $46, X Y, t(2 ; 13)(q 12 ; q 14), \quad t(12 ; 13)(q 21 ; q 14)$ emerged, with both chromosomes 13 involved in two different translocations. A homozygous breakpoint can occur by chance, and some at least certainly do, or its occurrence could be favoured in a 'breakable' zone (for example, a fragile site or sequence prone to rearrangement such as the immunoglobulin genes). A homozygous breakpoint at recessive antioncogene would not be favoured, but its occurrence would, in turn, cause or favour malignant disease. A proportion of CLL patients have recently been found to exhibit impaired retinoblastoma genes, and such may be the case in our patient.

Estimates of the frequency of chromosome abnormalities detectable in unselected newborns using moderate levels of banding

H WHITE, C BROWNE, C JOYCE Wessex Regional Genetics Laboratory, General Hospital, Fisherton Street, Salisbury SP2 7SX.

We have used data on structural chromosome abnormalities identified during prenatal diagnosis to estimate the number of such abnormalities that would be detectable in an unselected series of newborns using moderate levels of banding (400 to 500 bands). These data were compared with the rates detected in non-banded surveys of newborns. Between 1976 and 1990 prenatal diagnosis was carried out on 14677 women aged 35 and over. Among these we detected 112 structural rearrangements, 32 unbalanced and 80 balanced. These figures were adjusted by two approaches to give an estimate of the frequency of structural abnormalities in the newborn. Our data suggest that the use of moderate levels of banding increases the frequency of detection of unbalanced structural abnormalities from 0.052 to $0.061 \%$ and of balanced structural abnormalities from 0.212 to $0.522 \%$. Thus the total number of chromosome abnormalities detectable in the newborn is increased from $0.60 \%$ in unbanded preparations to $0.92 \%$ in banded preparations.

\section{What are the limits of normal variation?}

\section{N MESSARITI}

Cytogenetics Department, Nottingham City Hospital, Hucknall Road, Nottingham NG5 $1 P B$.

An unusual variant $9 \mathrm{qh}+$ was detected through routine cytogenetic analysis of a patient referred for mixed hearing loss and developmental delay. The variant was inherited from the father: there were no dysmorphic features or relevant family history. The karyotype was apparently normal. 9qh + variants are common, occurring in about $1 \%$ of the population, and as in this case, not presumed to have clinical significance. This variant is unusual owing to its strikingly large $9 \mathrm{qh}+$ region, being approximately $3 / 4$ of the size of the entire homologous chromosome 9. It represents an extreme example of the normal variation present in the human karyotype.

\section{Survey of adolescents with severe intellectual handicap}

J C ASTHANA, S SINHA, J S HASLAM, H M KINGSTON North West Regional Cytogenetics Service, St Mary's Hospital, Manchester.

A diagnostic survey was undertaken of children aged 11 to 19 years with severe learning 
difficulties $(I Q<50) ; 82$ children were identified and their medical records reviewed. A specific diagnosis for their retardation was documented in 25, 18 of whom had Down's syndrome. A probable aetiology or a disorder of unknown aetiology had been identified in a further 21. To confirm the existing diagnosis, identify new diagnoses, and offer genetic counselling, the parents of 63 children were offered detailed reassessment of their child; 53 children were reviewed and a specific disorder identified in 25 previously undiagnosed children. The most frequent diagnoses made were fragile $\mathrm{X}$ syndrome and Rett's syndrome. On completion of the survey, 61 had a specific diagnosis or probable aetiology identified, 12 had associated disorders such as cerebral palsy, and in only nine of the 82 children were there no clues at all to the cause of their retardation.

\section{Assessment of chromosome 21 aberrations by chromosome in situ suppression (CISS) with chromosome 21 specific library}

M N ISA, E BOYD, J TOLMIE, $\mathrm{J} M$ CONNOR

Duncan Guthrie Institute of Medical Genetics, Yorkhill Hospitals, Glasgow G38Sf.

Chromosomal in situ suppression (CISS) using a chromosome 21 specific library has been applied to complement standard cytogenetic techniques in several diagnostic cases where a chromosome abnormality was known or suspected to involve chromosome 21 . The cases studied include two different translocations between chromosome 21 and a non-acrocentric chromosome, and a case of a small additional chromosome suspected on clinical grounds of being derived from chromosome 21 . The library was labelled by direct incorporation of biotin 11-dUTP in the PCR amplifications and chromosome painting performed with modifications of the methods described by Pinkel et al (Proc Natl Acad Sci USA 1988;85:9138-42) and Lichter et al (Proc Natl Acad Sci USA 1988;80:223-34). The results confirmed that in the two translocations the extra material on chromosomes $\mathrm{X}$ and 2 was derived from the chromosome 21 .

\section{Six cases of sex mosaicism diagnosed by the Kennedy Galton Centre}

\section{TOOP, C STONE}

Kennedy Galton Centre, Level 8 CRC, Northwick Park Hospital, Watford Road, Harrow, Middlesex HA1 $3 U$ F.

Between 1986 and 1991 six cases with a mosaic sex karyotype were diagnosed postnatally by the Kennedy Galton Centre. Three were $45, X / 46, X Y$ and one each were 45 , $\mathrm{X} / 46, \mathrm{X}, \mathrm{r}(\mathrm{Y}), 45, \mathrm{X} / 47, \mathrm{X}, \operatorname{inv}(\mathrm{Y})+\operatorname{inv}(\mathrm{Y})$, and $45, X / 46, X, t(Y ; 21)$. The phenotypes were seen to range from: (1) apparently normal males, (2) newborn infants with ambiguous genitalia, (3) females with Turner stigmata. Variation in genital anomalies was also seen: (1) hypospadias, (2) streak ovaries, (3) female with apparently normal external genitalia, (4) enlarged clitoris/small phallus, (5) normal male genitalia.

\section{Deletion of $9 p$ in three generations without apparent phenotypic effect}

\section{PELLY, I BARNES}

Centre for Human Genetics, Langhill, 117 Manchester Road, Sheffield S10 5DN.

Chromosome analysis on the amniotic fluid from a 34 year old woman referred for maternal age showed that the female fetus had an apparently unbalanced karyotype with a small interstitial deletion of chromosome 9p. Parental blood was examined and the father was found to carry the same deletion, $46, \mathrm{XY}, \operatorname{del}(9)(\mathrm{p} 21.2 \mathrm{q} 22.1$ ). The deleted segment could not be detected elsewhere in the karyotype after high resolution analysis. The pregnancy continued to term and a phenotypically normal child was delivered, with normal development after four months. Family studies have shown that the grandmother also carries the deletion. There is no family history of obstetric problems, physical handicap, or mental retardation. In all other families reported so far deletions without phenotypic effect have been transmitted from the mother and it has been suggested that genomic imprinting may play a role in determining the phenotypic effect. In this case, however, the deletion has been transmitted, without effect, by both male and female family members; thus, imprinting does not seem to be applicable here.

\section{Another distal long arm deletion of the $X$ chromosome}

\section{MURPHY, P BATSTONE,} H SLATER

Cytogenetics Laboratory, Department of Pathology, Raigmore Hospital, Inverness.

Chromosome analysis was performed on a 30 year old woman who had presented with infertility $(\mathrm{PO}+\mathrm{O})$. At the time of referral to the cytogenetics laboratory her gonadotrophin levels had been in the menopausal range for six months and a diagnosis of ovarian failure had been made. Her karyotype was $46, X, \operatorname{del}(X)(q 26)$. A review of publications on $\mathrm{X}$ chromosome deletions and their phenotypes (Therman et al. Hum Genet 1990;85: 175-83) showed only 18 patients from 12 families with terminal or interstitial X chromosome long arm deletions with breakpoints at or distal to Xq25. The lack of Turner syndrome stigmata, apart from ovarian dysgenesis, in our patient and other distal $\mathrm{Xq}$ deletion cases illustrates the difficulty in the early ascertainment of people with this aberration. This case also adds to the data locating at least some of the genes determining normal ovarian function to Xq26-qter.

\section{A case of complete trisomy 10 in a liveborn}

\section{A BUTTERWORTH \\ E B ALLIBONE}

Regional Cytogenetics Unit and Department

of Histopathology, St fames's Hospital, Leeds LS9 7TF.

This case presented as an early neonatal death with multiple congenital abnormalit- ies. $\mathrm{G}$ banded analysis of blood lymphocyte cultures showed $47, \mathrm{XX},+10$ in all cells. No case of complete trisomy 10 in a liveborn has previously been pliblished. A comparison can be made between the present case and cases of mosaic trisomy 10 , where similarities include retrognathia, low set/dysplastic ears, and long, slender trunk. Cases of partial 10p or $10 \mathrm{q}$ trisomy also display some features seen in our case of complete trisomy 10 , for example, scoliosis and cardiac and renal abnormalities.

\section{A recombinant chromosome 3 arising from a familial inv ins(3)(p25.3q25q13.2)}

\section{K MADAN, F MENKO,}

A W M NIEUWINT

Cytogenetics Laboratory, O Central Hall 13, Polikliniek Building, Free University

Hospital, De Boelelaan 1117, $1081 \mathrm{HV}$ Amsterdam.

We report a recombinant chromosome 3 in a child with multiple congenital abnormalities, resulting from a familial inverted insertion, inv ins(3)(p25.3q25q13.2). The abnormal chromosome 3 in the child which has a duplication of the segment $3 \mathrm{q} 13.2 \rightarrow \mathrm{q} 25$ has arisen as a result of a crossover in the noninserted segment $\mathrm{p} 25.3 \rightarrow \mathrm{q} 13.2$ in the father. Two brothers of the father are also carriers of the inverted insertion. The clinical features of the child include dysmorphic facies with a relatively large head, broad nasal bridge, proptosis of the eyes with 'sunset' phenomenon, strabismus, coloboma of the optic nerve and glaucoma of the right eye, low set ears, bilateral cleft lip and palate, and a small mandible. Psychomotor retardation, feeding problems, and growth retardation were also present. This phenotype can be directly correlated to the duplication of the segment $3 \mathrm{q} 13.2 \rightarrow \mathrm{q} 25$ as there is no concurrent deletion of any other chromosome segment.

\section{A case of mosaic partial trisomy 9 confirmed by chromosome painting}

\section{P R MILLER, M W STACEY,} C GOULD

Regional Cytogenetics Unit, Birmingham Maternity Hospital, Edgbaston, Birmingham B15 2TG; Regional Cytogenetics Unit, East Birmingham Hospital, Bordesley Green East, Birmingham.

A 14 month old child with microcephaly and cerebral palsy was referred for cytogenetic investigation. Blood lymphocytes showed a $46, \mathrm{XY} / 47, \mathrm{XY},+$ mar karyotype, the marker being present in $40 \%$ of the cells examined. By investigation with a number of conventional staining techniques ( $G$ banding, $C$ banding, silver staining, and methyl green/ Hoechst fluorescent staining), it was postulated that the marker was most likely to be a ring chromosome comprised of the centromere and proximal $p$ and $q$ arms of chromosome 9. The marker was confirmed to be derived from chromosome 9 by fluorescence in situ hybridisation ('chromosome painting') with a chromosome 9 specific DNA library. 
De novo interstitial deletion of chromosome 15 (q25.1q26.1) in a moderately retarded adult female

\section{A RUTTER}

Regional Cytogenetics Unit, St fames's Hospital, Leeds.

A mildly dysmorphic 18 year old girl with moderate learning difficulties was referred for investigation of short stature and delayed puberty. She was found to have a de novo interstitial deletion of chromosome 15, her karyotype being 46,XX,del(15)(q25.1q26.1). Deletions of the $15 \mathrm{q} 2$ to qter region have rarely been described. The proband had features in common with other reported cases including a prominent nasal bridge, hypoplastic nostrils, thin upper lip, truncal obesity, growth retardation, and hypotonia (Martin et al. F Med Genet 1990;27:637-9). Hexosaminidase A levels were within the normal range for a homozygote. The deletion does not therefore include the HEX A locus, previously assigned to $15 \mathrm{q} 23$ to $\mathrm{q} 24$. The pyruvate kinase $\mathrm{PKM}_{2}$ locus has also been assigned to chromosome $15 \mathrm{q} 2$ to qter. The patient's deleted cell line may be used to pinpoint the $\mathrm{PKM}_{2}$ locus.

\section{De novo inverted duplication of chromosome $7 q$}

\section{J S HASLAM, A NORMAN}

North West Regional Cytogenetics Service, St Mary's Hospital, Manchester.

We present a case of a de novo inverted duplication of the long arm of chromosome 7 with macrocephaly, prominent occiput, downward slanting palpebral fissures, hypertelorism, and bilateral talipes equinovarus. Chromosome analysis showed the karyotype to be $46, X X$,inv dup(7)(pter $\rightarrow$ q36.1::q36.1 $\rightarrow$ $\mathrm{q} 22:: \mathrm{q} 36.1 \rightarrow \mathrm{qter})$ resulting in a duplication of the region $7 \mathrm{q} 22 \rightarrow \mathrm{q} 36.1$. Duplications are uncommon events and a search of published reports showed only $\mathbf{4 0}$ previous reports of any duplication involving the long arm of chromosome 7. Only two of these previous reports are of de novo duplications and only four do not have any other chromosomal abnormalities. Only one of the previously reported cases is of a duplication of $7 \mathrm{q} 22 \rightarrow 36.1$. All the dysmorphic features present in our case were also present, along with a number of other dysmorphic features, in the reported cases. These additional features possibly result from the associated chromosome deletion. This indicates the importance of single chromosome alterations in assessing clinical effects.

\section{A deletion of chromosome 2 in a child with Waardenburg syndrome}

K H TURNBULL, A P READ, C FOY, V E NEWTON

Regional Cytogenetics Unit, St Mary's Hospital, Hathersage Road, Manchester M13 OFH.

A deletion of the long arm of chromosome 2, $46, X Y, \operatorname{del}(2)(q 34 q 36.2)$, was found in a child

with features typical of Waardenburg syndrome. This reinforces recently published linkage analysis work mapping the Waardenburg gene to this region.

\section{Deletion of chromosome 1q43 associated with agenesis of the corpus callosum and other midline defects} T L CHAMBERS, B S SPEIDEL, $P$ SEDDON

$S$ W Regional Cytogenetics Centre, Southmead Hospital, Bristol BS10 5NB.

We report four infants all having loss of material from the distal part of the long arm of chromosome 1 at band $q 43$. These patients were noted to have certain concordant clinical abnormalities including consistent midline defects. (1 and 2) Two unrelated male infants were investigated because of midline cleft palate, short neck, low set ears, hypospadias, and absent corpus callosum. Analysis showed an unbalanced karyotype: $46, X Y$, $\operatorname{del}(1)(q 43)$. (3) A male neonate was investigated because of midline cleft palate, bulbous nose, epicanthic folds, low set ears, and agenesis of the corpus callosum. Analysis showed an unbalanced karyotype: $46, \mathrm{XY}$, $\operatorname{mar}(1)$. (4) A female neonate was investigated for growth retardation, dysmorphism, and midline defects. Analysis showed an unbalanced karyotype: $46, \mathrm{XX},-1,+\operatorname{der}(1), \mathrm{t}(1 ; 10)$ (q43;q25.3)pat. Agenesis of the corpus callosum can be detected by ultrasound scan. Isolated cases of agenesis of the corpus callosum is a rare occurrence but when associated with other midline defects may indicate the presence of a deletion at 1q43 or trisomy for chromosome 8,13 , or 18 .

\section{Bloom's syndrome: cytogenetic confirmation in a photosensitive 21 year old male}

\section{MURPHY, P BATSTONE, L FORSYTH, N FRASER \\ Cytogenetics Laboratory, Department of \\ Pathology, Raigmore Hospital, Inverness.}

The incidence of this rare autosomal recessive chromosome breakage syndrome has been estimated at 1:160000 in Ashkenazi Jews and considerably lower in gentile populations. Positive cases therefore rarely present within the laboratory. We describe our experiences with one such case. Cytogenetic analysis was performed on a 21 year old male clinically diagnosed as having Bloom's syndrome. The patient, who was of small stature and had been photosensitive from an early age, was the son of consanguineous Scottish parents. The first sample exhibited a 10 -fold increase in sister chromatid exchanges (SCEs) but as only a small number of cells were available for analysis a repeat was requested. This showed a 5 -fold increase in spontaneous chromosome breakage and an 11 -fold increase in SCEs over control levels. Quadriradial figures resulting from chromatid exchanges were also noted.

\section{Coffin-Siris syndrome and fra(10)(q25.2): a coincidence?}

\section{J L HURET, D BONNEAU, D COUET, J TANZER \\ Cytogenetique, Lab Hematologie, CNRS}

1338 CHU la Miletrie, Poitiers, France.

A 3 year old girl from a moderately mentally retarded mother showed height, weight, and head circumference below the 3rd centile, mental retardation, sparse scalp hair, body hirsutism, hypoplastic fifth finger- and toenails, and Coffin-Siris syndrome was diagnosed. The karyotypes of the patient and her mother both exhibited a recurrent break in 10q25.2. Re-examination of the mother suggested Coffin-Siris syndrome. Although the presence of fra(10)(q25), a known fragile site, may well be coincidental, a direct relationship between Coffin-Siris syndrome and the karyotypic anomaly cannot be excluded.

\section{Cutis laxa with Marfanoid habitus: this syndrome maps with B1 laminin at 7 q31.3}

\section{J L HURET*, D BONNEAU*, G GODEAU,$+ M$ LARREGUE* CHU Poitiers* and Creteil $\dagger$, France.}

A case of cutis laxa with Marfanoid habitus exhibited a recurrent $\operatorname{ctb}(7)(\mathrm{q} 31.3)$ in the band where the B1 laminin gene has been mapped. Laminin protein could not be detected in the basement membranes. A published case bore a translocation involving 7q31. We studied the laminin activity in another patient with cutis laxa and Marfanoid habitus and again laminin could not be detected. Other cases are required to confirm that this syndrome maps to $7 \mathrm{q} 31.3$ and results from a defect in $\mathrm{B} 1$ laminin.

\section{National Down Syndrome Register: 1989/90}

R IDE, D E MUTTON, M BOBROW, E ALBERMAN

The National Down Syndrome Cytogenetic Register, Department of Epidemiology and Medical Statistics, The London Hospital Medical College at QMW, Mile End Road, London E1 4NS.

The Register now contains 2096 cases for $1989 / 90$ and is providing new and comparative information on prenatal and clinical diagnoses of trisomy 21 in England and Wales. The proportion of cases registered after prenatal diagnosis in 1990 has risen $4 \%$ over 1989. In 1990, 42 cases were confirmed subsequent to serum screening in its various forms, a three-fold increase on the previous year. The proportion of prenatal diagnoses after an abnormal ultrasound scan was also $2 \%$ above the 1989 level. A total of 747 births registered for 1989 were compared at the Office of Population Censuses and Surveys (OPCS) with the 488 reported to the congenital malformations register; 431 cases were matched $(57 \cdot 7 \%)$. Fifty-seven cases notified to OPCS could not be found on the cytogenetic Register. Attempts are being made to improve both sets of data. The Register is continuing to be funded by the Medical Research Council. 


\section{Discordant cytogenetics in a dizygotic in vitro fertilisation twin pregnancy}

\section{P HORSFIELD}

Regional Cytogenetics Unit, St fames's University Hospital, Beckett Street, Leeds.

A 39 year old mother carrying 15/40 w IVF twins presented for amniocentesis because of maternal anxiety. Chromosome analysis of routinely cultured amniocytes showed the following karyotypes. Twin 1: 46,XY,der (12),t(8;12)(q24.21;q24.32). Twin 2: 46,XX, $t(8 ; 12)(q 24.21 ; q 24.32)$. Subsequent examination of the parents' lymphocytes showed a normal mother and the father carried the same balanced $t(8 ; 21)$ as twin 2 . As the unbalanced karyotype of twin 1 would probably have resulted in severe abnormalities with the possibility of early spontaneous abortion of the pregnancy, the parents opted for selective in utero termination of twin 1 . A blood sample from a heart puncture of twin 1 at termination confirmed the unbalanced karyotype. Twin 2 was subsequently delivered normally and displayed a normal phenotype. This case clearly illustrates the importance of screening gamete donors in IVF pregnancies when the underlying causes of infertility are not known.

\section{A rare case of a false negative finding in both direct and long term culture of a chorionic villus sample}

\section{$M$ WHITEHOUSE, L PINDAR, K OCRAFT \\ Department of Cytogenetics, City Hospital,} Hucknall Road, Nottingham NG5 1PB.

Prenatal diagnosis by first trimester chorionic villus sampling on a 43 year old patient resulted in a normal $46, \mathrm{XX}$ karyotype in both direct preparation and long term culture. Following an abnormal ultrasound scan and a subsequent stillbirth at 28 weeks' gestation, fibroblast culture showed a karyotype of $47, \mathrm{XX},+18$ in all cells examined. $\mathrm{Al}$ though it is generally considered that long term culture more closely reflects fetal karyotype, this case clearly illustrates that discrepancies can occur.

\section{A double translocation carrier detected by chorionic villus investigations}

\section{A WILKINSON, K OCRAFT Interdisciplinary Centre for Medical Genetics, Old B Block, City Hospital, Nottingham NG5 $1 P B$.}

A 24 year old woman was referred for prenatal diagnosis because of a known, apparently balanced chromosome translocation in her husband, $t(4 ; 15)(4 p 15 p ; 4 q 15 q)$. The husband was one of four brothers, one of whom had produced unbalanced offspring. Chromosome analyses of a chorionic villus sample showed the presence of the paternal translocation, plus an additional apparently balanced translocation, $t(12 ; 18)(12 p 18 p ; 12 q 18 q)$, of unknown origin. Inheritance of two translocations, one from each parent, would be a rare event, and the possibility of a false positive finding had to be considered. However, further investigations (maternal blood sampling and amniocentesis) confirmed the presence of the second translocation in the fetus and its maternal origin. As far as we are aware this represents the first report of a genuine double translocation detected by chorionic villus sampling.

\section{Cytogenetic investigation of a three way translocation}

A DUNLOP, F GLENCROSS, N MORRISON, M CROUCH, E MORRISON, J TOLMIE, E BOYD

Duncan Guthrie Institute of Medical Genetics, Yorkhill Hospitals, Glasgow G3 8SF.

Chromosome analysis of peripheral blood lymphocytes from a 27 year old woman referred because of a poor obstetric history (para $2+4$ ) showed a three way rearrangement involving chromosomes 7 and 11 : 46,XX,t $(7 ; 11) \quad(7 \mathrm{pter} \rightarrow 7 \mathrm{p} 21:: 7 \mathrm{q} 31 \rightarrow 7 \mathrm{p} 21::$ $11 \mathrm{p} 15 \rightarrow 11$ pter;11qter $\rightarrow 11 \mathrm{p} 15:: 7 \mathrm{q} 31 \rightarrow 7 \mathrm{qter})$. Subsequent amniocentesis showed a male fetus with an apparently identical translocation. In situ hybridisation using biotinylated pHINS indicated the break in the short arm of chromosome 11 to be at distal $11 \mathrm{p} 15.5$. The proband exhibits none of the clinical features reported in cases of interstitial deletions of the short arm of chromosome 7 (Speleman et al. $\mathcal{F}$ Med Genet 1989;26:52832) or of the long arm of chromosome 7 (Morey and Higgins. Am $\mathcal{F}$ Med Genet 1990;35:95-9), suggesting the rearrangement is balanced. Flow cytometry studies are in progress.

\section{A reciprocal translocation chimeric conceptus}

\section{P N SCRIVEN, Z DOCHERTY}

Paediatric Research Unit, 8th Floor Guy's Tower, Guy's Hospital, St Thomas's Street, London SE1.

A 28 year old translocation carrier, 46, $\mathrm{XX}, \mathrm{t}(17 ; 21)(\mathrm{q} 23 ; \mathrm{q} 22.1)$, was referred for chorionic villus sampling. At 10 weeks' gestation the fetus was normal for dates but no heart beat was detectable. After evacuation, placenta and fetal skin were cultured for chromosome analysis. Two cell lines were detected in the placenta with GTG banding: $46, \mathrm{XX}, \mathrm{t}(17 ; 21)(\mathrm{q} 23 ; \mathrm{q} 22.1)$ mat (32/50 cells) and $46, X X,-21,+\operatorname{der}(21) t(17 ; 21)(\mathrm{q} 23 ; \mathrm{q} 22.1)$ mat $(18 / 50$ cells). Examination of variable chromosome regions indicated that the two cell lines originated from different fertilisations, and excluded the possibility of uniparental disomy for chromosome 17. Only one cell line was found in skin from the fetus: $46, X X, t(17 ; 21)(q 23 ; q 22.1)$ mat (100 cells). It was concluded that fusion of two zygotes at a very early stage of development had probably resulted in a chimeric morula, with subsequent development producing a conceptus with a non-chimeric embryo, and chimerism confined to the chorion. However, the possibility that two zygotes implanted, but that one fetus was subsequently resorbed (a 'vanishing twin') cannot be excluded.
Discovery prenatally of a cell line containing two separate balanced reciprocai translocations together with a normal cell line: $46, X X / 46, X X, \operatorname{rcp}(1 ; 7)(p 32 ; q 32)$, $\operatorname{rcp}(2 ; 11)(\mathbf{p} 21 ; q 23)$

B GOLDIE

Medical Genetics Laboratory, University of Aberdeen, Foresterhill, Aberdeen AB9 2ZD.

Analysis of an amniotic fluid sample from a 39 year old woman referred for age showed one culture with 69 normal and 95 abnormal (two balanced reciprocal translocations) female mitotic divisions. A second culture produced the ratio 77 normal:8 abnormal divisions. Two further cultures produced a total of 18 divisions without the translocations. Examination of the fetus on termination at 20 weeks showed a cleft palate, camptodactyly of the left hand with overlapping 2nd and 5th fingers, low set ears, and a short beaked nose. Unfortunately, none of the tissues obtained at necropsy cultured successfully. To find two separate reciprocal translocations within a cell line is unusual. For that cell line to appear in mosaic form makes this case very rare.

\section{A fetal karyotype with three cell lines involving two different abnormalities}

\section{J ELLIOTT, I C S BARNES}

Centre for Human Genetics, Langhill, 117 Manchester Road, Sheffield S10 5DN.

Chromosome analysis on an amniotic fluid sample taken at 21 weeks' gestation because of a maternal age of 35 years showed a female fetus with three cell lines involving two different de novo abnormalities. These comprised an extra, bisatellited marker and an apparent duplication/deficient chromosome 7 with monosomy of the distal portion of the long arm (q36-qter) and duplication of most of the short arm (p11-pter). The cell lines were: (1) $46, \mathrm{XX},-7+\operatorname{rec}(7)$, dup $\mathrm{p}$, inv $(7)(\mathrm{p} 1 \mathrm{qq} 36)$, (2) $47, \mathrm{XX},+\operatorname{mar}$, (3) $47, \mathrm{XX},+\operatorname{mar},-7+$ rec(7), dup p,inv(7)(p11q36). The pregnancy was terminated at 23 weeks' gestation. The major cell line in all tissues cultivated except the lymphocytes was that with both abnormalities present. There are two possible explanations for the origin of the mosaic 7 cell lines: (1) postzygotic origin with unequal mitotic crossing over, or (2) prezygotic origin based on a meiotic half chromatid duplication model (Cantu et al. Ann Genet (Paris) 1985;28:254-7).

\section{Prenatal diagnosis of}

Pallister-Killian syndrome: low level mosaicism or pseudomosaicism?

\section{J S W DIACK, T BROWN, J C S DEAN} Medical Genetics, Foresterhill, Aberdeen.

A 38 year old woman with low serum AFP was referred for amniocentesis. In one out of four amniocyte cultures, 15 out of 83 cells had the karyotype $47, X Y,+i(12 p)$. The remaining cells had a normal male karyotype. This mosaicism is found in Pallister-Killian 
syndrome, a tissue limited mosaic syndrome characterised by multiple malformations and abnormal facies. On termination a male fetus was delivered and certain clinical features consistent with Pallister-Killian syndrome were noted: malformed right ear, single palmar crease, protruding upper lip, and hydronephrotic kidney. Cultures from skin, placenta, lung, liver, and cord blood were established. Analysis of 50 cells from a minimum of three cultures from each tissue type failed to show $i(12 p)$. As might be expected the peripheral lymphocytes were also negative for the isochromosome ( 50 cells). It is suggested that the mild clinical features may reflect a very low level of mosaicism in the fetus. Alternatively the tissue results may indicate pseudomosaicism in the amniocytes.

\section{Trisomy/partial monosomy 13 mosaicism associated with relatively mild clinical malformation}

\section{P DUCKETT, H J PORTER, I D YOUNG \\ Cytogenetics Department, Phase III, Leicester Royal Infirmary, Leicester $L E 15 W W$.}

A female fetus with a de novo chromosome abnormality involving mosaicism with two abnormal cell lines was diagnosed on amniocentesis. Karyotyping showed a single normal chromosome 13 together with in one cell line a $t(13 q 13 q)$ Robertsonian translocation chromosome (that is, trisomy 13), and in the other a small ring chromosome which had presumptively originated as a postzygotic event from the $t(13 q 13 q)$ chromosome (that is, partial monosomy 13). The pregnancy was terminated at 19 weeks. The fetus was found to have normal growth parameters, and external examination and necropsy showed only minor abnormalities. The phenotype in this fetus together with three previously described similar cytogenetic cases was less severe than might have been expected. The possibility that the effects of the trisomy and monosomy may have counterbalanced each other at the tissue level in embryogenesis, thereby resulting in less disturbance of morphogenesis than would be predicted for each type of imbalance acting in isolation, is considered.

\section{A satellited chromosome 2 detected at prenatal diagnosis}

J ELLIOTT, I C S BARNES

Centre for Human Genetics, Langhill, 117 Manchester Road, Sheffield S10 5DN.

Fetal karyotyping following amniocentesis at 16 weeks' gestation in a 35 year old showed a male karyotype with a satellited region on the distal short arms of chromosome 2. Silver staining and $\mathrm{C}$ banding techniques confirmed the presence of NOR material on the abnormal chromosome and on all the acrocentric chromosomes indicating an apparently unbalanced rearrangement. Parental karyotyping showed that the phenotypically normal mother carried the same satellited 2 also in an unbalanced form.

\section{A review of ring chromosome 13 syndrome following a prenatal diagnosis case}

\section{A BLISSITT, L WILLIAMS}

Regional Cytogenetics Unit, Birmingham Maternity Hospital, Edgbaston, Birmingham B15 2TG.

Following a prenatal diagnosis case in which a ring chromosome 13 was found, it was discovered that five other cases with a $r(13)$ had been diagnosed at our laboratory since 1980. Their clinical features are compared with the clinical features of five other published cases of ring chromosome 13 syndrome (Martin et al. Hum Genet 1982;61:18-23, Fried et al. Clin Genet 1975;7:203-8, Parcheta et al. Eur $\mathcal{F}$ Pediatr 1985;144:409-12). Unfortunately no further clinical information was received on two of our cases. Of the other four cases reported by our laboratory, we only have information on one child who is still alive. One baby died at the age of 6 days and two were prenatal diagnosis cases which resulted in termination of the pregnancies. From the information that was obtained, the clinical features of the 11 cases were seen to be very similar. 